\title{
T玨 SMIB \& MULTI-MACHINE SYSTEM DESIGN OF COORDINATED BASED CONTROLLER USING JAYA ALGORITHM
}

\author{
Ruchi Patel $^{1}$, Raunak Jangid ${ }^{2}$, Kapil Parkh ${ }^{3}$, Sagar Trivedi ${ }^{4}$
}

E-Mail Id: raunak.ee85@gmail.com

${ }^{1}$ M.tech Student, ${ }^{2,3,4}$ Assistant Professor, Electrical Engineering, SITE, Nathdwara(Raj.)

Abstract-Power system is a huge network which involves many operations going on at the same time. Hence, it is very complex. This complexity is susceptible to many abnormal conditions which may give rise to the low frequency oscillations causing instability in the operation. These low frequency oscillation ranges from $0.1 \mathrm{~Hz}$ to 2Hz. It is most commonly addressed via incorporating Power System Stabilizer (PSS) in the system. But the elimination of oscillations by it may not be sufficient if the oscillations are due to the severe fault condition. In such a case, Flexible AC Transmission devices (FACTs) come to the aid consisting of several useful characteristics depending upon the type of device used. For the present work, use of Static Synchronous Compensator (STATCOM) has been made. Here, a structure has been designed in cooperating PSS and damping controller based on STATCOM for the purpose of damping out low frequency oscillations. STATCOM is added as the supplementary damping controller. The capability of structure is further enhanced by the use of JAYA Algorithm (JA) by optimizing its parameters. This developed optimized structure is then implemented in the Single Machine Infinite Bus System (SMIB) to analyze its performance. A two are four machine system has been developed and given design of PSS has been implemented for each of machines in their respective areas. To realize the whole model the platform was provided by the MATLAB/SMIULINK. Later on, the performance of the proposed structure for damping out controllers is compared with the other heuristic algorithm based controllers so as to show its vitality and robustness. The main focus which has been considered is the speed deviation at nominal, light and heavy loading conditions. The system modeled is tested for these loading conditions after deviation in speed with and without CPSS, and then with JAYA tuned coordinated design of CPSS and STATCOM. The results obtained have been tabulated and compared in different fault conditions with and without CPSS.

Keywords: Power System Stabilizer, FACTs, STATCOM, JAYA Algorithm, Single Machine Infinite Bus System.

\section{INTRODUCTION}

Consumer loads always vary during the entire length of the day and hence power received by them also changes accordingly. Another reason for the change in power at the consumer end is due to the disturbance on any part of the power system network. This brings into the focus the importance of stable operation in power system for maintaining the good quality power supply continuity. Stability of a power system is when it is able to come back to its stable operating point after being disturbed within a least amount of time. A power plant consists of several generating units all with different voltage rating which has to be connected to the bus terminals with same phase sequence and frequency for the stable operation. This is said to be synchronized operation of power plant. Therefore, whenever power system undergoes certain disturbances it lost its synchronism for that particular time [3]. Stability of a power system is affected by transients or disturbances, here more specifically the disturbance due to low frequency oscillations has been discussed and addressed. These low frequency oscillations typically range between (0.1 to 2$) \mathrm{Hz}$ is further divide into local $(0.7$ to $2 \mathrm{~Hz})$ and inter area $(0.1$ to $0.8 \mathrm{~Hz})$ mode. To stabilizes the power system operation it was damped out by using a commonly used device Power System Stabilizer (PSS). But it also doesn't provide full extended damping in case of certain abnormal conditions due to certain serve fault conditions. Hence, Flexible AC Transmission Devices (FACTS) which has become popular in recent times can be used. As it is well known that it is a very big family of power electronics based devices and many of these devices have already been put into use for solving the given problem. These are mainly group into four categories; Series, Shunt, ShuntSeries and Series-Series Controllers. Here, from the Shunt controller, Static Synchronous Compensator (STATCOM) which is very useful in power flow management and voltage regulation, have been put into use for the propose[32].

A combination of PSS and STATCOM based controller has been designed for damping out low frequency oscillations with enhanced performance. The performance of the controller could further be enhanced with the aid of certain optimization techniques. Few techniques which have already been used are genetic algorithm (GA); particle swarm optimization (PSO); gravitational search algorithm and Teacher learner Based Optimization (TLBO). The very new technique have been used here with the developed controller, to further extend the reach of designed damping controller, its parameter has been optimized and for it JAYA Algorithm (JA) is made use of. To test this developed controller MATLAB/SIMULINK platform is provided [14].

DOI Number: 10.30780/IJTRS.V04.I05.003

pg. 16

WwW.ijtrs.com

www.ijtrs.org

Paper Id: IJTRS-V4-I5-005 
ISSN No.: 2454- 2024 (online)

\section{SYSTEM MODEL}

\subsection{STATCOM Overview \& its Control System}

Static synchronous compensator (STATCOM) is generally a controlled reactive-power source and it provides voltage support by generation or absorption of reactive power at a common coupling point without the necessity of capacitor banks or external reactors. The functional block diagram representation of STATCOM is shown in fig. 2.1. It has a DC energy source or for the role of source SCR controlled capacitor or even SCR controlled inductor can be used. It generates and absorbs the reactive power depending upon the requirement.

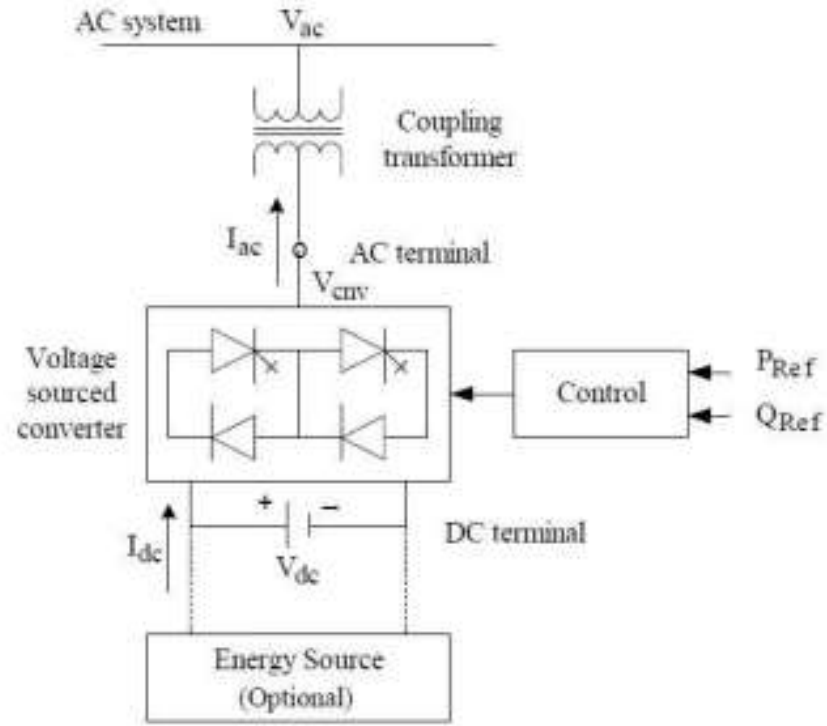

Fig. 2.1 Functional Block Diagram of STATCOM

It can also provide active power if connected to a source. It is also useful to reduce fluctuations in voltages. The basic use of it is to improve power factor along with the regulation of voltage of the system it is connected to and therefore, also useful in maintaining voltage stability of the system[15].

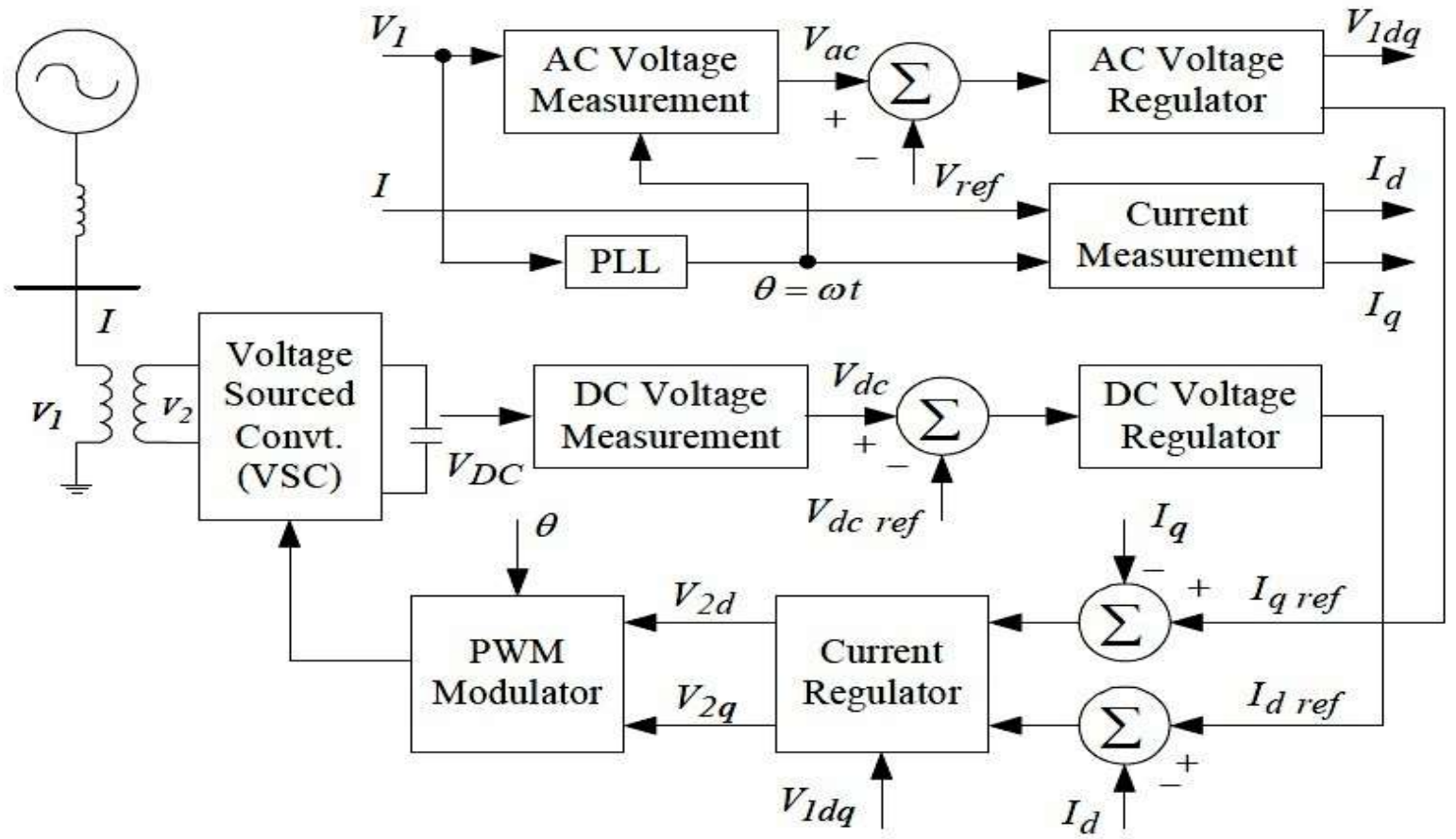

Fig.2.2 STATCOM with its Control System

The above figure represents the single line diagram of STATCOM with its control system. It has Phase Locked loop (PLL) for synchronization of positive sequence components, measuring system for $\mathrm{d}$ and $\mathrm{q}$ axis $\mathrm{AC}$ voltage-current 


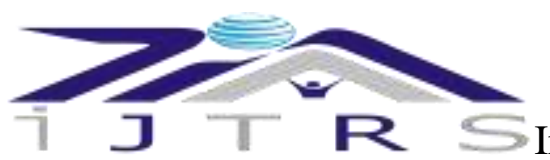

International Journal of Technical Research \& Science

positive sequence components along with DC voltage, Voltage regulation loop having AC and DC voltage regulator and Inner current regulation loop having current regulator.

\section{PROPOSED APPROACH}

\subsection{Power System Stabilizer (PSS)}

Due to high gain and fast response excitation system gives good transient stability. The frequencies of the oscillations lies in the range of $(0.2$ to 2$) \mathrm{Hz}$ which are very low. This kind of excitation as mentioned above with fast AVR adds to the instable nature of power system. And this instable nature is accompanied by low frequencies oscillation as just mentioned which can remains there or continue to grow in magnitude. Hence, there is need of damping the instable nature i.e. low frequency oscillations efficiently. Here comes for rescue PSS which provides damping to the oscillations of rotor of the generator via controlling its excitation using auxiliary stabilizing signal. It acts as a supplementary controller in the system of excitation. Below is the basic block diagram of PSS.

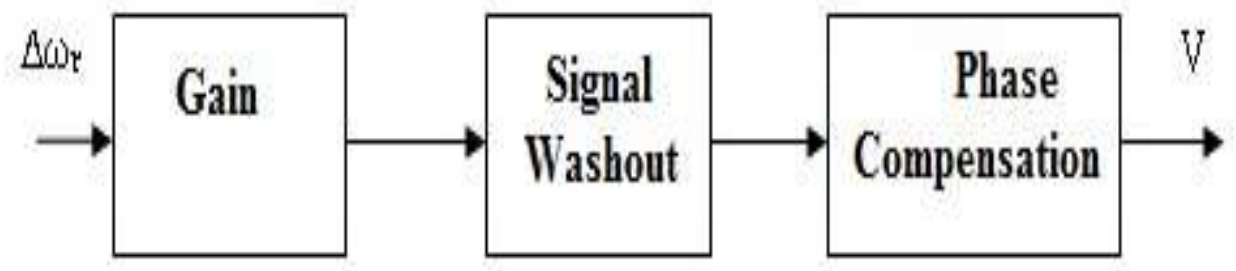

Fig.3.3 Power System Stabilizer (PSS)

It has three blocks: Gain, Signal Washout and Phase Compensation. Its input is change in speed and output is voltage which is input to AVR[16].

\subsection{Modeling of PSS}

The first block gain determines the degree to which damping has to be given and hence it should generally equals to the setting for maximum damping. But it can also vary depending on other situations. The signal washout block is a high pass filter. It has high time constant $\mathrm{T}_{\mathrm{w}}(1-20$ seconds $)$ which allows signals with $\omega_{\mathrm{r}}$ to pass on without any change and thus enables PSS to give response only to change in speed. the block number three is phase compensation block which comprises of here two stage lead lag network. It compensate for the phase lag of input to exciter and electrical torque of generator.The output of PSS $\mathrm{V}_{\text {PSS }}$ is provided to excitation system where it will add to $\mathrm{V}_{\text {ref }}$ which is the reference voltage of excitation system.

$$
\begin{aligned}
& \frac{d V_{1}}{d t}=K_{P S S} \frac{d \Delta \omega}{d t}-\frac{1}{T_{w}} V_{1} \\
& \frac{d V_{2}}{d t}=\frac{T_{1}}{T_{2}} \frac{d V_{1}}{d t}+\frac{1}{T_{2}} V_{1}-\frac{1}{T_{2}} V_{2} \\
& \frac{d V_{P S S}}{d t}=\frac{T_{3}}{T_{4}} \frac{d V_{2}}{d t}+\frac{1}{T_{4}} V_{2}-\frac{1}{T_{4}} V_{P S S}
\end{aligned}
$$

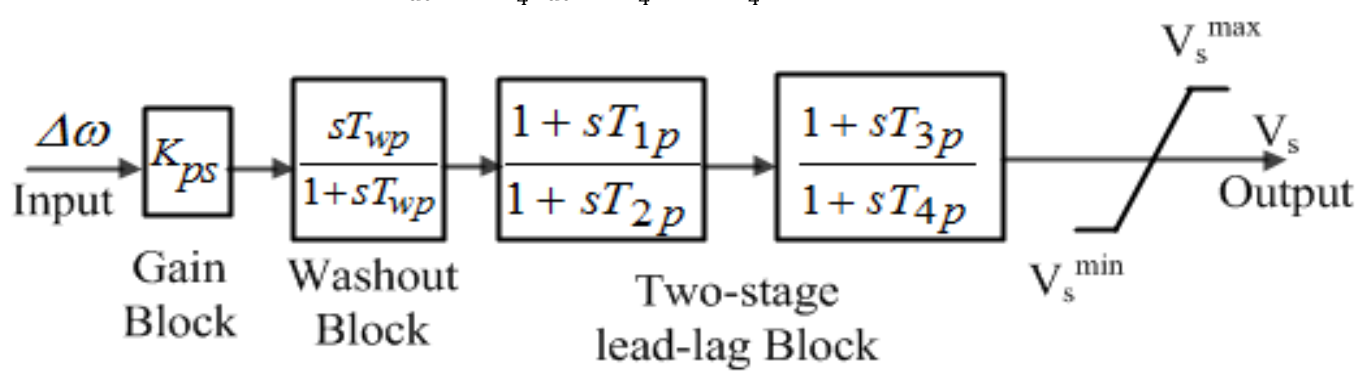

Fig.3.4 Structure of PSS

\section{MULTI MACHINE SYSTEM AND JAYA TUNED STATCOM AND COORDINATED CPSS}

\subsection{Multi Machine Power System}

It can be designed and modeled same as single machine system with following sets of assumptions,

$>$ Every synchronous machine in the system is represented by its constant voltage E behind $\mathrm{X}_{\mathrm{d}}$. Here, saliency and flux has been neglected.

$>$ Constant input power.

$>$ Admittances to ground for all loads are equivalent via pre fault bus voltages.

$>$ Ignoring asynchronous effect along with damping effect.

$$
\begin{aligned}
& \text { www.ijtrs.com } \\
& \text { www.ijtrs.org }
\end{aligned}
$$




\section{$\longrightarrow$ \\ $>\delta_{\mathrm{m}}=\delta$}

$>$ All machines in a single station will swing simultaneously, hence called as coherent machine and can be taken as single machine [gul2016].

The model is used only for the transient condition studies only for period of $1 \mathrm{sec}$ or $1^{\text {st }}$ swing. On supposing the linear damping characteristics $4^{\text {th }}$ assumption is bettered. An add-on of damping torque to initial torque in swing equation is done. The damping torques has electrical and mechanical components. Hence, displaying damping on turbine, generator and electrical load's damping effect. Multi machine system solution,

Initial power flow, bus voltage and phase angle,

Load equivalent admittance,

$$
\begin{gathered}
I_{i}=\frac{s_{i}^{*}}{V_{i}^{*}}=\frac{P_{i}-j Q_{i}}{V_{i}^{*}} \\
E_{i}=V_{i}+j X_{d}^{\prime} I_{i}
\end{gathered}
$$

System nodal equation,

$$
Y_{i 0}=\frac{P_{i}-j Q_{i}}{\left|V_{i}\right|^{2}}
$$

At steady state before any disturbances, electrical and mechanical output are given as,

Swing equation,

$$
P_{e i}=P_{m i}=\operatorname{Re}\left\{E_{i}^{*}, I_{i}\right\}=\sum_{j=1}^{m}\left|E_{i}^{\prime}\right|\left|E_{j}^{\prime}\right|\left|Y_{i j}\right| \cos \left(\theta_{i j}-\delta_{i}+\delta_{j}\right)
$$

$$
\frac{H d^{2} \delta_{i}}{\pi f_{0} d t^{2}}=P_{m i}-\sum_{j=1}^{m}\left|E_{i}^{\prime}\right|\left|E_{j}^{\prime}\right|\left|Y_{i j}\right| \cos \left(\theta_{i j}-\delta_{i}+\delta_{j}\right)=P_{m i}-P_{e i}
$$

$Y_{i j}=$ faulted reduced bus admittance matrix element

Swing equation state variable model,

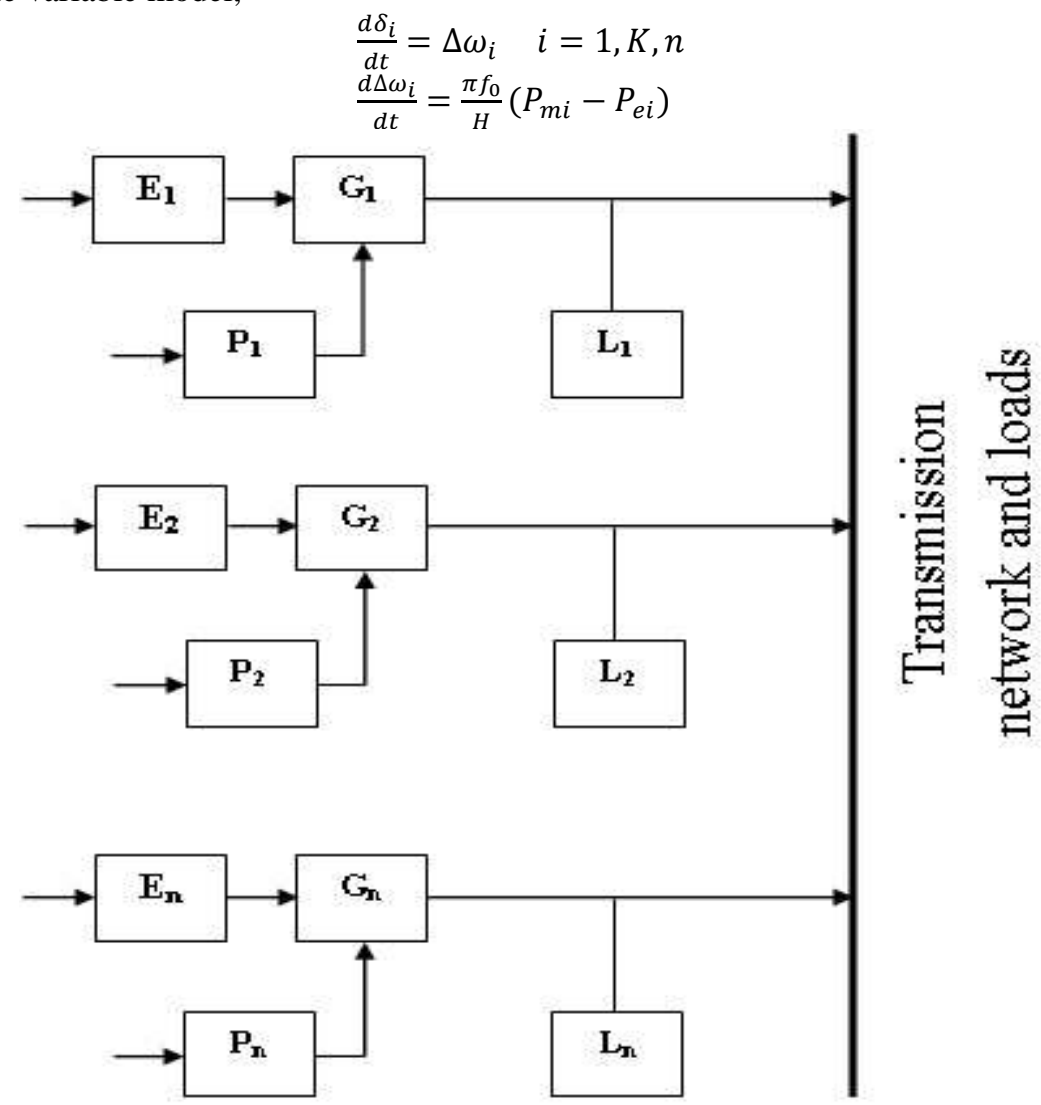

Fig.5: Multi Machine system Schematic

The above figure represents the multi machine schematic with $n$ machines system, here $P$ is the prime mover, $G$ is the synchronous machine and $\mathrm{E}$ is the excitation system.

\subsection{Four Machine Two Area System}

Considering the multi-machine type here, Kundur's four machine two area machine systems has been employed and tested. In simple words, the stability analysis has been carried out on a system where two areas are interconnected 


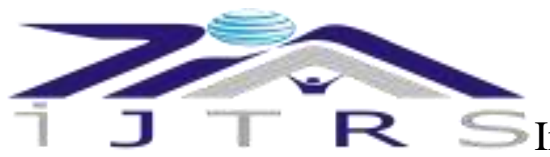

\section{International Journal of Technical Research \& Science}

via a tie line and each area has two generating units or simply machines [Dhanraj2016]. The two machines with in an area are in synch with each other and also the two areas are in synch. It has two lines with $230 \mathrm{kV}$ interconnecting two fully symmetrical areas and is $220 \mathrm{~km}$ long. It was designed especially for studying the low frequency oscillation in a large interconnected system. Irrespective of the small size in actual operation it depicts the nature of typical system. As mentioned each area has two round generators $(20 \mathrm{kV} / 900 \mathrm{MVA})$.

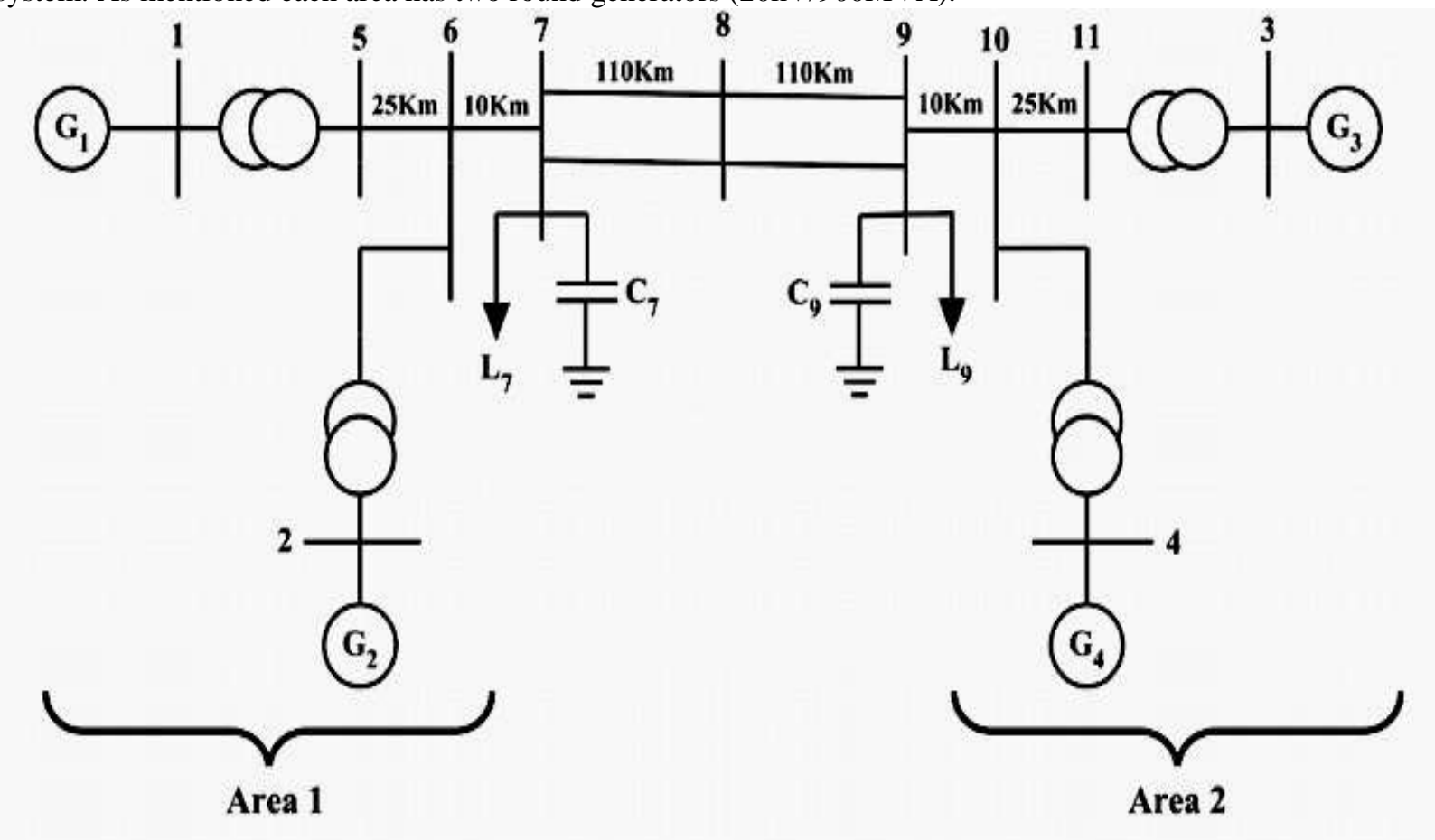

Fig. 4.1 4 Machine 2 Area System

Machines are identical in all respect except their inertia (area $1 \mathrm{H}=6.5 \mathrm{~s}$, area $2 \mathrm{H} 6.175 \mathrm{~s}$ ). At all the locations, identical speed regulators are assumed with 200 gain fast acting exciter. All the generators are equipped with PSS.

\subsection{Jaya Algorithm}

Most of the optimization techniques has algorithm which are parameter specific. Some common examples are GA, PSO, DE and ABC etc. Hence, for the process it is essential to take care and control these algorithm specific parameters. And if something goes wrong while setting the value of these parameters it would lead increased calculations and thus leads to the local best possible solution. If these so called algorithm specific parameters are not used in the process but using controlling parameters as population size, number of generations etc. it would be more beneficial. This key point has lead to the creation of teaching learning-based optimization (TLBO) and which in turn has given raise the new algorithm having only one phase of operation instead two as in TLBO known as Jaya Algorithm (JA).

JA is very simple and clear. Jaya is the Sanskrit word which means victory. Here, effort is always for the optimal solution while putting aside the worst solution. Therefore, it wins i.e. victory on achieving optimal solution [10].

\subsection{PROCESS of JA}

For any iteration there are two candidates, best and worst. The best candidate will always have best value of the function $\left(\mathrm{f}(\mathrm{x})\right.$ ) denoted as $\mathrm{f}(\mathrm{x})_{\mathrm{b}}$ while worst will have worst value of $\mathrm{f}(\mathrm{x})$ denoted as $\mathrm{f}(\mathrm{x})_{\mathrm{w}}$. Note, the best and worst solution is chosen from the pool of solutions of candidates. Certain assumptions are,

$f(x)=$ objective function to be minimized

$\mathrm{i}=$ iteration

$\mathrm{j}=$ designed variables

$\mathrm{m}=$ number of designed variables $(\mathrm{j}=1,2, \ldots, \mathrm{m})$

$\mathrm{k}=$ population size

$\mathrm{n}=$ number of candidate solution $(\mathrm{k}=1,2 \ldots, \mathrm{n})$

For any random iteration $\mathrm{i}^{\text {th }}, \mathrm{k}^{\text {th }}$ candidate,

$\mathrm{j}^{\text {th }}$ variable $=\mathrm{X}_{\mathrm{j}, \mathrm{k}, \mathrm{i}}$ (value) 

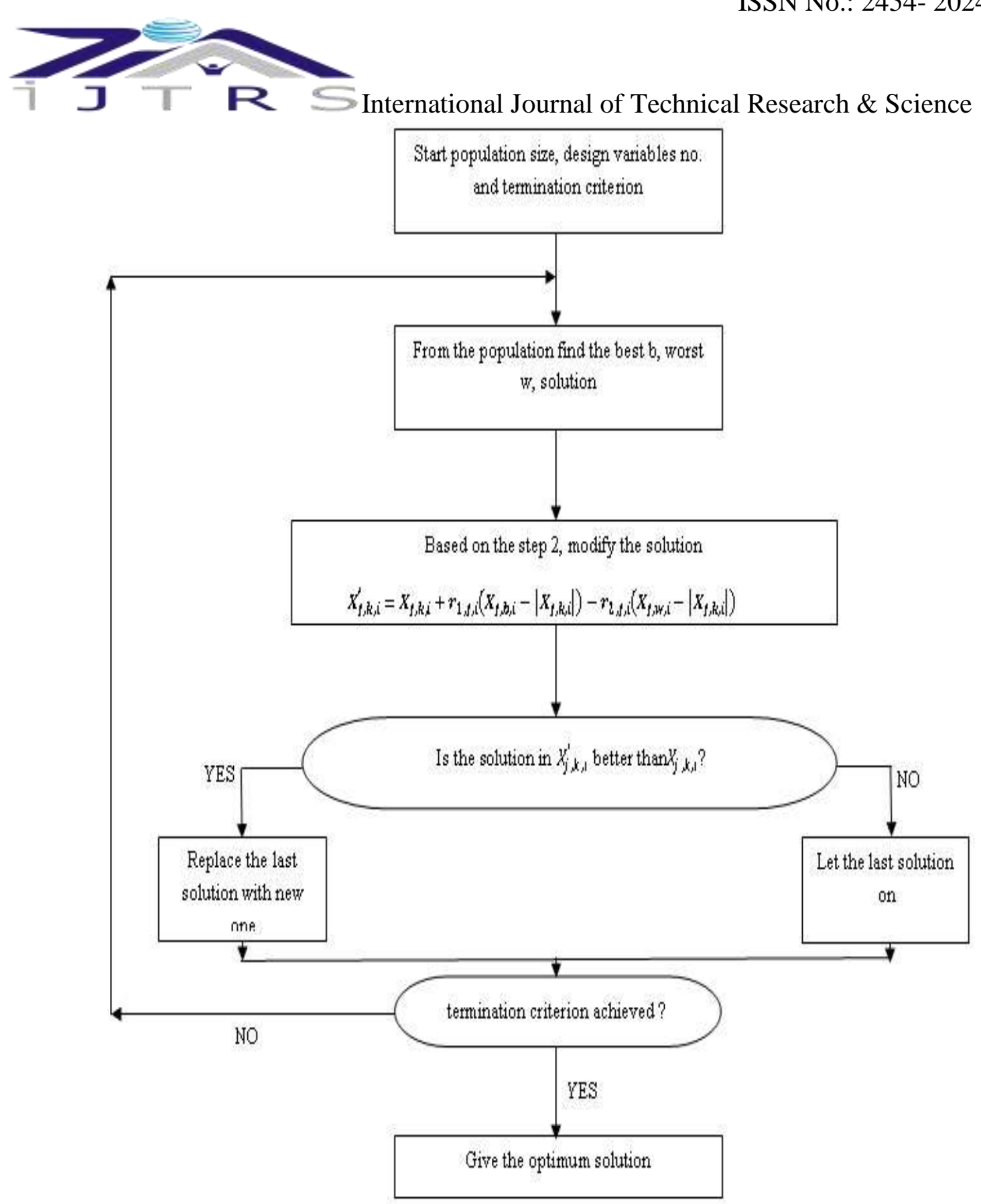

Fig.4.2 Flow Chart of Jaya Algorithm

The above value of variable is modified as for $\mathrm{i}^{\text {th }}$ iteration within $[0,1]$,

where,

$$
\mathrm{X}_{\mathrm{j}, \mathrm{k}, \mathrm{i}}^{\prime}=\mathrm{X}_{\mathrm{j}, \mathrm{k}, \mathrm{i}}+\mathrm{r}_{1, \mathrm{j}, \mathrm{i}}\left(\mathrm{X}_{\mathrm{j}, \mathrm{b}, \mathrm{i}}-\left|\mathrm{X}_{\mathrm{j}, \mathrm{k}, \mathrm{i}}\right|\right)-\mathrm{r}_{2, \mathrm{j}, \mathrm{i}}\left(\mathrm{X}_{\mathrm{j}, \mathrm{w}, \mathrm{i}}-\left|\mathrm{X}_{\mathrm{j}, \mathrm{k}, \mathrm{i}}\right|\right)
$$

$\mathrm{X}_{\mathrm{j}, \mathrm{b}, \mathrm{i}}=$ Best candidate value of $\mathrm{j}^{\mathrm{th}}$ variable

$\mathrm{X}_{\mathrm{j}, \mathrm{w}, \mathrm{i}}=$ Worst candidate value of $\mathrm{j}^{\text {th }}$ variable

$\mathrm{X}_{\mathrm{j}, \mathrm{k}, \mathrm{i}}^{\prime}=\mathrm{X}_{\mathrm{j}, \mathrm{k}, \mathrm{i}}$ 's modified value

$r_{1, j, i}, r_{2, j, i}=$ nay tow arbitrary number for $j^{\text {th }}$ variables

$r_{1, j, i}\left(X_{j, b, i}-\left|X_{j, k, i}\right|\right)=$ represents inclination of solution towards best solution

$-r_{2, j, i}\left(X_{j, w, i}-\left|X_{j, k, i}\right|\right)=$ represents affinity of solution to evade worst solution

If the $\mathrm{X}_{\mathrm{j}, \mathrm{k}, \mathrm{i}}^{\prime}$ has the better value than the $\mathrm{X}_{\mathrm{j}, \mathrm{k}, \mathrm{i}}$, then it will be maintained and treated as the input to the next iteration.

\section{RESULTS \& DISCUSSIONS}

The results of the developed simulation models under different contingencies are presented and discussed below. The developed model is simulated without STATCOM and PSS controller, with CPSS controller and with

$$
\begin{aligned}
& \text { www.ijtrs.com } \\
& \text { www.ijtrs.org }
\end{aligned}
$$


J I R S International Journal of Technical Research \& Science

STATCOM and PSS controller (Tuned by Jaya). The responses with and without controlled are accessed to examine the efficiency and strength of the CPSS and STATCOM controller. In order to optimize the (STATCOM+PSS) damping controller parameters, JAYA is used. Before using JAYA for optimization some parameters need to be provided like maximum number of iterations, population size, lower bound of scaling factor, upper bound of scaling factor. The JAYA can work effectively only when these parameters are chosen carefully. The various parameters chose for JAYA for SMIB \& MMPS are given in Table 5.1 \& 5.3 below.

Table-5.1 Various Parameters of Jaya at SMIB System

\begin{tabular}{|c|l|c|}
\hline S. No. & \multicolumn{1}{|c|}{ Parameter } & Value \\
\hline 1. & Maximum Number of Iterations & 50 \\
\hline 2. & Population Size & 05 \\
\hline 3. & Lower Bound of Scaling Factor & {$[1 \mathrm{e} 110 \mathrm{e}-110 \mathrm{e}-11 \mathrm{e} 11 \mathrm{e}-41 \mathrm{e}-4]$} \\
\hline 4. & Upper Bound of Scaling Factor & {$[1 \mathrm{e} 21 \mathrm{e} 11 \mathrm{e} 15 \mathrm{e} 11 \mathrm{e}-21 \mathrm{e}-2]$} \\
\hline
\end{tabular}

Table-5.2 STATCOM \& PSS Controller Parameters for SMIB System Tuned by Jaya

\begin{tabular}{|c|c|c|c|c|c|c|c|}
\hline \multirow{2}{*}{ S. No. } & \multirow{2}{*}{ System } & \multicolumn{3}{|c|}{ STATCOM Parameter Tuned by Jaya } & \multicolumn{3}{|c|}{ PSS Parameter Tuned by Jaya } \\
\cline { 3 - 8 } & & $\mathrm{K}$ & $\mathrm{T}_{1}$ & $\mathrm{~T}_{3}$ & $\mathrm{~K}_{\mathrm{P}}$ & $\mathrm{T}_{1 \mathrm{P}}$ & $\mathrm{T}_{2 \mathrm{P}}$ \\
\hline 1. & SMIB & 10 & 1.0369 & 1.0 & 23.7391 & 0.01 & $1 \mathrm{e}-4$ \\
\hline
\end{tabular}

Table-5.3 Various Parameters of Jaya at MMPS System

\begin{tabular}{|c|c|c|}
\hline S. No. & Parameter & Value \\
\hline 1. & Maximum Number of Iterations & 50 \\
\hline 2. & Population Size & 05 \\
\hline 3. & Lower Bound of Scaling Factor & $\begin{array}{l}\text { [1e0 1e-2 100e-2 1e0 1e-2 100e-2 1e0 1e-2 100e-2 1e2 1e-1 } \\
\text { le-1] }\end{array}$ \\
\hline 4. & Upper Bound of Scaling Factor & $\begin{array}{l}\text { [1e1 1e-1 200e-2 1e1 1e-1 200e-2 1e1 1e-1 200e-2 3e2 1e0 } \\
\text { 1e0] }\end{array}$ \\
\hline
\end{tabular}

Table 4: JAYA Optimized Parameters of STATCOM Controller and PSSs for four Machine two Area System

\begin{tabular}{|c|c|c|c|c|c|}
\hline Controller/Parameters & STATCOM & PSS1 & PSS2 & PSS3 & PSS4 \\
\hline GAIN & 208.6762 & 5.1301 & 1.3417 & 5.4467 & 5.0990 \\
\hline TIME CONSTANT & 0.9688 & 0.0137 & 0.0691 & 0.0100 & 0.0394 \\
\hline & 0.9682 & 1.8420 & 1.3131 & 1.4446 & 1.7969 \\
\hline
\end{tabular}

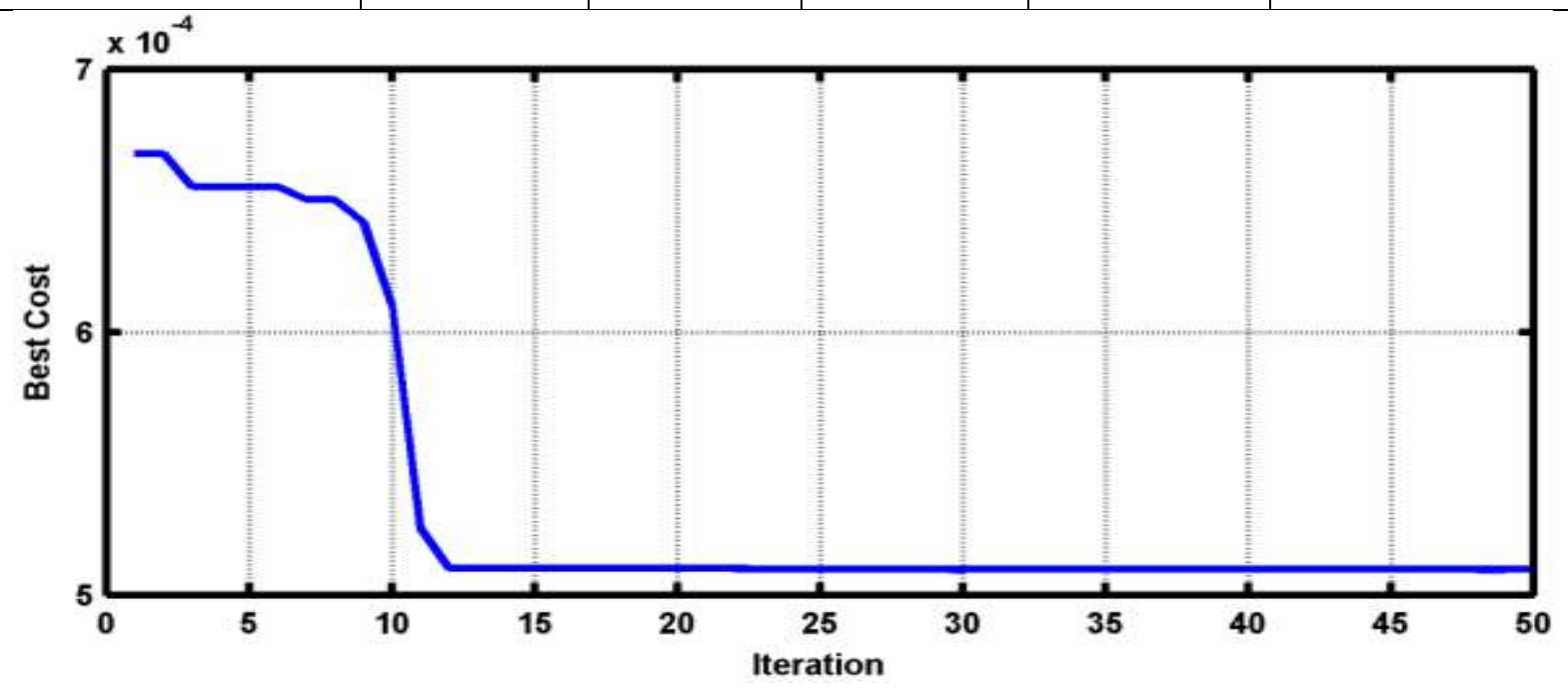

Fig.5.1 Convergence of Objective Function for Best Cost in SMIB System

DOI Number: 10.30780/IJTRS.V04.I05.003

pg. 22

Www.ijtrs.com

Www.ijtrs.org

Paper Id: IJTRS-V4-I5-005 


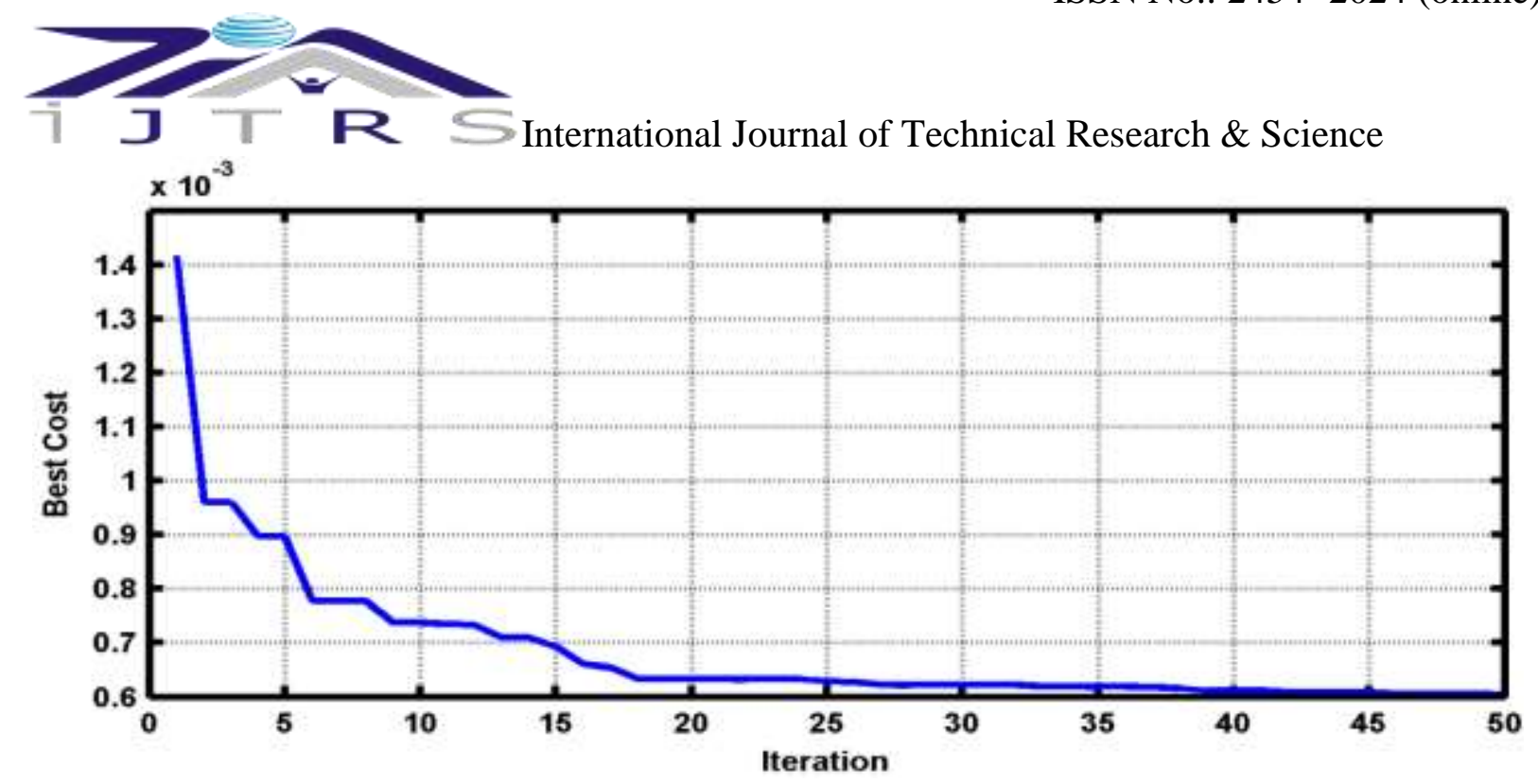

Fig. 5.2 Convergence of Objective Function for Best Cost in MMPS System

Table-5.5 Inter-Area and Local-Area Mode of Multi-Machine System at Various Fault

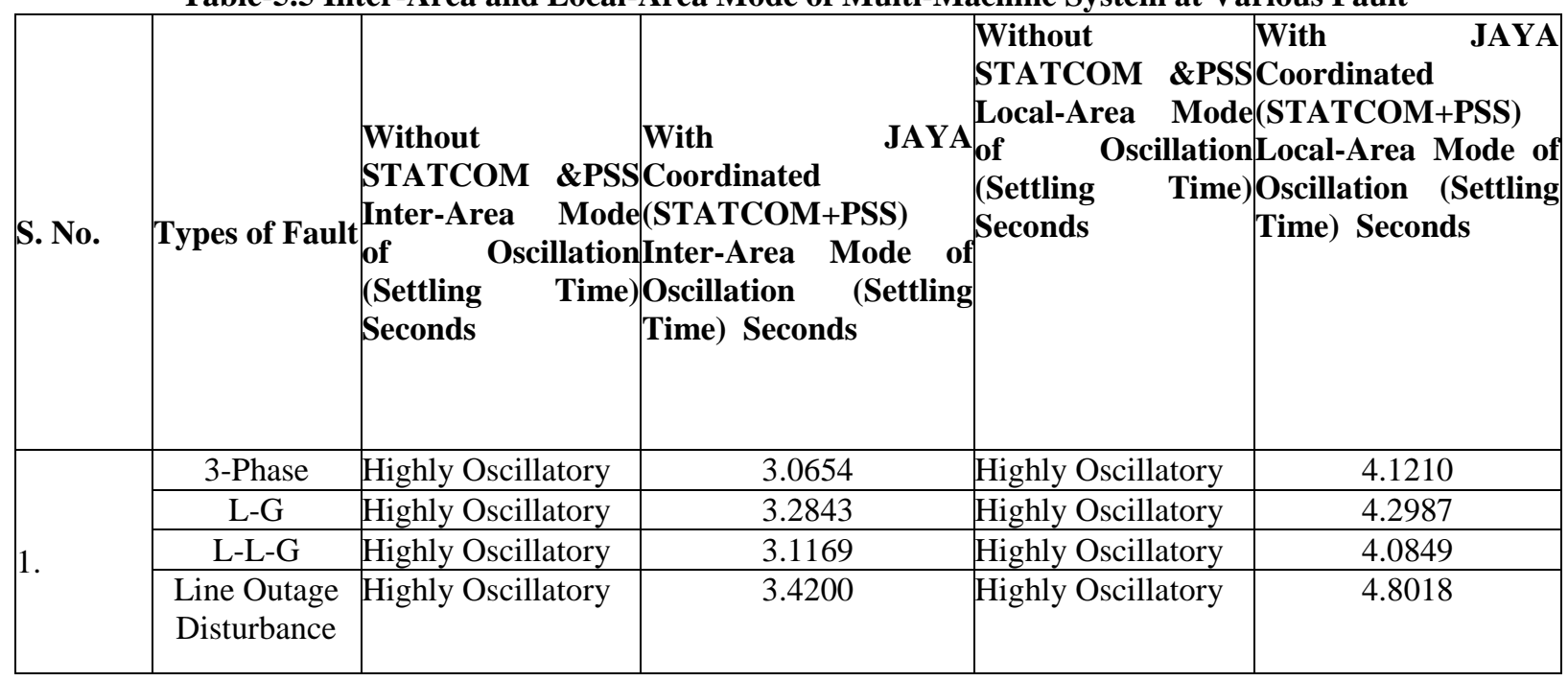

It is conclude that Table 5 speed deviation for MMPS system in various cases obtained as local area mode of oscillation and inter area mode of oscillation without controller (without PSS and STATCOM controller) the system response is high oscillatory and unstable but when we use control scheme (with CPSS and coordinated controller tuned by Jaya) system operate stable condition and settle down very quickly and system shows effective performance.

\section{CONCLUSION}

In the context of this thesis following things have been covered and addressed with utmost integrity, which is described below:

$>$ The model of SMIB has been developed with integrated action of STATCOM and CPSS so to analysis it for the various conditions as discussed and mentioned.

> A multi machine system consisting of two areas each having two machines have been developed. And, the same controllers are implemented too.

$>$ Also, the integrated design of STATCOM and CPSS has been tuned successfully with the implementation of JAYA algorithm.

$>$ In the case of speed deviation the system behavior is highly oscillatory with nominal, light and heavy loading. But when JAYA tuned CPSS and controller were used in SMIB, the system is very responsive and settle down quickly to be stable. 
J T $R$ S International Journal of Technical Research \& Science

$>$ The settling time after deviation in speed have been reduced approximately to 0.8 to $1.5 \mathrm{sec}$ in case of nominal, light and heavy loading conditions when JAYA tuned CPSS and coordinated STATCOM was in use.

$>$ Moreover, each loading conditions has been tested and verified for different faults namely 3 phase fault, L-L and L-L-G fault.

$>$ Overall the system stability increases when speed is varying.

\section{REFERENCES}

[1] S. Raj and B. Bhattacharyya, "Optimal placement of TCSC and SVC for reactive power planning using Whale optimization algorithm", Swarm and Evolutionary Computation BASE DATA, pp. 1-29, 2018.

[2] A. Haldera, N. Palb and D. Mondalc, "Transient Stability Analysis of a Multimachine Power System with TCSC Controller - A Zero Dynamic Design Approach”, Electrical Power and Energy Systems 97, pp. 51-71, 2018.

[3] KM Sreedivya ; P Aruna Jeyanthy and D Devaraj, "Fuzzy logic based power system stabilizer for damping low frequency oscillations in power system." In Innovations in Electrical, Electronics, Instrumentation and Media Technology (ICEEIMT), 2017 International Conference on, pp. 201-205. IEEE, 2017.

[4] S Sharma and S Narayan, "Damping of low frequency oscillations using robust PSS and TCSC controllers." In Computing, Communication and Networking Technologies (ICCCNT), 2017 8th International Conference on, pp. 1-7. IEEE, 2017.

[5] MK Sharma, A Vijay and G N Pillai, "Stable Type-2 Fuzzy Logic Control of TCSC to Improve Damping of Power Systems", International Conference on Computer, Communications and Electronics (Comptelix, pp. 388393), July 2017.

[6] E Yasoubi and M Sedighizadeh, "Coordinated Design of PSS and TCSC Controllers using Colonal selection algorithm for stability enhancement of dynamical power system”, IEEE, pp. 580-585, 2017.

[7] M D Kumar and P Sujatha, "Design and Development of Self Tuning Controller for TCSC to Damp Inter Harmonic Oscillation", Energy Procedia 117, pp. 802-809, 2017.

[8] DK Mishra, A Mohanty and P Ray, "MATLAB/SIMULINK based FA for optimizing TCSC controller in a power system", ICACCS -2017, Jan 2017.

[9] M Bakhshi, Md H Holakooie and A Rabiee, "Fuzzy based damping controller for TCSC using local measurements to enhance transient stability of power systems", Electrical Power and Energy Systems 85, pp. 12-21, 2017.

[10] SP Singh, T Prakash, VP Singh and MG Babu, "Analytic hierarchy process based automatic generation control of multi-area interconnected power system using Jaya algorithm." Engineering Applications of Artificial Intelligence 60, pp. 35-44, 2017.

[11] A. K. B. Patel and P. D. Raval and D. Patel, "A SSSC Based Damping controller for Stability enhancement of power system", 3rd International Conference on Advances in Electrical, Electronics, Information, Communication and Bio-Informatics, pp. 2-5, 2017.

[12] T. Cheng, M. Chen, P. J. Fleming, Z. Yang and S. Gan, "An effective PSO-TLBO algorithm for multi objective optimization", IEEE Congress on Evolutionary Computation, pp. 3977-3982, 2016.

[13] D. Kumar, V. Gupta and R. C. Jha, "Implementation of FACTS Devices for Improvement of Voltage Stability using Evolutionary Algorithm", 1st IEEE International Conference on Power Electronics; Intelligent Control and Energy Systems, pp. 1-6, 2016.

[14] R Rao, "Jaya: A simple and new optimization algorithm for solving constrained and unconstrained optimization problems." International Journal of Industrial Engineering Computations 7, no. 1, pp. 19-34, 2016.

[15] K Hawisa, R Ibsaim and A Daeri, "Voltage Instability Remedy using FACTS, TCSC Compensation First A.", Sciences and Techniques of Automatic control \& computer engineering - STA'2016, pp. 104-107, Dec 2016.

[16] H Hasanvand, Md R Arvan, B Mozafari and T Amraee, "Coordinated design of PSS and TCSC to mitigate interarea oscillations", Electrical Power and Energy Systems 78, pp. 194-206, 2016.

[17] H. N. Arcos, F. L. Quilumba and J. C. Cepeda, "Tuning of Power System Stabilizers - An Ecuadorian Case Study”, IEEE PES Transmission \& Distribution Conference and Exposition - Latin America (PES T\&D-LA), 2016. 